\title{
Perspektiven der repräsentativen Demokratie
}

\author{
Jan Philipp Schaefer
}

Die Demokratie ist ohne Feinde. ${ }^{1}$ Kein politisches System weltweit möchte heute mehr ,undemokratisch" sein. ${ }^{2}$ Demokratie ist in allen großen westlichen Staaten im Wesentlichen repräsentativ organisiert, teilweise mit plebiszitären Einsprengseln. In der politischen Philosophie lange mit Skepsis betrachtet, ${ }^{3}$ hat sich die Herrschaft des Demos - Projektionsfläche politischer Affekte ${ }^{4}$ - von einer „Kultur des Westens“ ${ }^{\text {“5 }}$ zum universalen Leitbild guter Ordnung gewandelt. Der Vertrauensvorschuss, den die Demokratie als solche genießt, erstreckt sich jedoch nicht gleichermaßen auf alle ihre Varianten. Unter dem Eindruck von Privatisierungs- und Supranationalisierungstendenzen greift unter Politikwissenschaftlern eine mit dem Schlagwort „Postdemokratie“ umrissene Skepsis um sich, die sich besonders auf die mittelbare Demokratie bezieht. ${ }^{6}$ Dies gibt Anlass, die Perspektiven demokratischer Repräsentation näher auseinanderzusetzen. Die

1 M.G. Schmidt, Geschichtliche Entwicklungslinien der Demokratie in: H. Bauer/ P.M. Huber/K.-P. Sommermann (Hrsg.), Demokratie in Europa, 2005, S. 21 (22).

2 P.M. Huber, Demokratie in Europa - Zusammenfassung und Ausblick in: H. Bauer/ ders./K.-P. Sommermann (Hrsg.), Demokratie in Europa, 2005, S. 491 (492).

3 Siehe dazu den Abriss bei: I. Blühdorn, Simulative Demokratie, 2013, S. 35 ff. M. Greven, War die Demokratie jemals modern? Oder: des Kaisers neue Kleiner, Berliner Debatte Initial 2009, S. 67 (73) erschien die Demokratie noch vor kurzem als „Relikt der Vormoderne“.

4 I. Blühdorn, Simulative Demokratie, 2013, S. 24 f. meint, dass man von „Demokratie“ im Plural sprechen müsse. Siehe auch ders. aaO, S. 41: „Demokratie“ als „grundlegend umstrittener Begriff“ und ,historisch offenes Projekt".

5 So noch die implizite These des Sammelbandes von M. Greven (Hrsg.), Demokratie - eine Kultur des Westens?, 1998.

6 Es griffe allerdings zu kurz, wollte man die postdemokratische Skepsis gegen die repräsentative Demokratie auf ein Lob des Plebiszits zuspitzen. Indem die Postdemokratie-These behauptet, dass Vermachtungsprozesse innerhalb der Gesellschaft die parlamentarischen Institutionen zur Theaterbühne verkommen lassen, wird (wenn auch versteckt) eine Spitze gegen die direkte Demokratie geäußert. Denn diese kann man auffassen als eine besonders selektive Repräsentation: die der gesellschaftlich einflussreichsten Subjekte, deren Fragemacht das Volk zu einer Antwort herauszufordern vermag (E.-W. Böckenförde, Demokratische Willensbildung 
folgenden Überlegungen beruhen auf vier gedanklichen Schritten: Ansetzend am Befund eines weltweiten Triumphs der Demokratie (I.) wird die Krise ihrer repräsentativen Form erläutert (II.). Mit Bezug zum Grundgesetz wird sodann untersucht, was die postdemokratische Wende für die repräsentative Demokratie bedeuten könnte (III.). Endlich gilt ein Ausblick den Begriffen „Souveränität“ und „Legitimation“, die in ähnlicher Weise wie „Repräsentation“ unter postdemokratischen Druck geraten (IV.).

\section{Vom Triumph der Demokratie zu ihrer postdemokratischen Infragestellung}

Historisch in der Glorious Revolution, im nordamerikanischen Unabhängigkeitskampf sowie im revolutionären Frankreich radiziert, ${ }^{7}$ hat die Demokratie jeden Despotismusverdacht widerlegt. Dass der globale Triumph der Regierung des Volkes durch das Volk und für das Volk (Abraham Lincoln) ihre Befürworter jeglicher Begründungs-, Beweis- und Rechtfertigungslasten enthebt, legt die wissenschaftliche Unergiebigkeit einer Reflexion auf ihre Bedingungen und Prinzipien nahe: „Ce qui va de soi n'a pas besoin d'être pensé“ .8 Doch diese Argumentationsweise schließt Konkordanz mit Konsens kurz. Demokratie ist selbstreflexiv, insoweit Zweifel an ihr demokratieadäquat und für die Anpassungsfähigkeit des politischen Systems unerlässlich sind. ${ }^{9}$ Jüngste Äußerungen, wonach die Demokratie manchem unter der Last der Auseinandersetzung mit autoritären Gegenentwürfen zur „lahmen Dame“ wird, ${ }^{10}$ legen eine erhebliche Diskursdynamik in Politik- und Rechtswissenschaft offen. Im Anschluss an die Ent-

und Repräsentation in: J. Isensee/P. Kirchhof (Hrsg.), HStR III, 3. Auflage 2005, $\S 34$, Rn. 7).

7 U. Volkmann, Setzt Demokratie den Staat voraus?, AöR 127 (2002), S. 575 (579).

8 L. Heuschling, Krise der Demokratie und der juristischen Demokratielehre in Frankreich in: H. Bauer/P.M. Huber/K.-P. Sommermann (Hrsg.), Demokratie in Europa, 2005, S. 33 (44) zur französischen rechtswissenschaftlichen Demokratietheorie.

9 S. Augsberg, Gesellschaftlicher Wandel und Demokratie: Die Leistungsfähigkeit der parlamentarischen Demokratie unter Bedingungen komplexer Gesellschaften in: H.M. Heinig/J.P. Terhechte (Hrsg.), Postnationale Demokratie, Postdemokratie, Neoetatismus, 2013, S. 27 (29).

10 H. Münkler, Lahme Dame Demokratie: Wer siegt im Systemwettbewerb?, Internationale Politik 65/3 (2010), S. $10 \mathrm{ff}$. 
scheidungen des Bundesverfassungsgerichts in Sachen „Maastricht“ und „Lissabon“ diskutiert man fachübergreifend soziokulturelle Demokratieprämissen. Ernst-Wolfgang Böckenförde nennt folgende Einflussfaktoren gelingender Demokratie: ${ }^{11}$

- die Garantie persönlicher Freiheit in einer von tradierten Stammes- und Sippenstrukturen emanzipierten Gesellschaft,

- die Abwesenheit theokratischer Legitimationsmuster der öffentlichen Gewalt, insbesondere eines religiösen Fundamentalismus,

- ein entwickeltes Schulsystem und eine urteilsfähige Aktivbürgerschaft,

- angemessene Komplexität und Beurteilbarkeit von Entscheidungsparametern,

- transparente, allzeit abrufbare Informationen über das politische Geschehen sowie ein ergebnisoffener, vorurteilsfreier Austausch über öffentliche Belange,

- Steuerbarkeit der Gesellschaft durch allgemein-politische Entscheidungen,

- ein demokratisches Ethos wechselseitiger Rücksichtnahme und Verständigungsbereitschaft.

Erneut wird auch das Verhältnis der Demokratie zum Rechtsstaat hinterfragt. ${ }^{12}$ Die jüngsten Demokratiebewegungen im Nahen Osten (,Arabellion“) und in Europa („Occupy“, „Democracia Real YA!“ etc.) rufen nach Rule of law mit weniger Verve als sie politische Mitbestimmung einfordern; menschenrechtliche Garantien werden tendenziell für selbstverständlicher genommen als demokratische Gleichheit. Der Aufmerksamkeitsvorsprung, den Mitbestimmung vor Menschenrechten genießt, scheint mir auf einen Kult der Parteinahme (durchaus mit dem Beigeschmack eines Klassenkampfes) zurückzuführen. Indem wir im öffentlichen Raum aufgefordert werden, uns zu unseren Meinungen zu bekennen, appelliert die Demokratie an unsere Selbstgewissheit, auf der „richtigen Seite“ zu stehen. Sie spornt uns an, Freiheit als Wagnis und Wettstreit zu begreifen. Demgegenüber relativiert der Liberalismus demokratische Gestaltungsoptionen unter zwei sich ergänzenden Gesichtspunkten. Die Verfassungsbindung der parlamentarischen Gesetzgebung nimmt uns die Angst vor der in kontingenter Dezision eines bindungslosen Volkes aufscheinenden Anarchie.

11 E.-W. Böckenförde, Demokratie als Verfassungsprinzip in: J. Isensee/P. Kirchhof (Hrsg.), HStR II, 3. Auflage 2004, § 24, Rn. 60 ff.

12 C. Mouffe, The Democratic Paradox, 2005. 
Grund- und Menschenrechte antworten auf unser Unbehagen an der Mehrheitsregel, indem sie der politischen Freiheit (Meinungs-, Versammlungsund Vereinigungsfreiheit, Wahl- und Petitionsrecht) durch großzügig bemessene, „in dubio pro libertate“ auszulegende Schrankenbestimmungen einen in seinem Innersten unantastbaren Deliberationsraum einrichten. Wenn eine Entgegensetzung von Rechtsstaatlichkeit und Demokratie richtig ist, dann besteht sie in einer Differenz der Haltungen, nicht des Herkommens oder der Strukturen. Ebendies kommt in der gängigen Rede vom „demokratischen Rechtsstaat" zum Ausdruck. Rechtsstaatlichkeit entspringt der Furcht: der Abwehrhaltung des Menschen, der sich seiner Freiheit unsicher ist. Demokratie ist Folge der Zuversicht in die eigene Gestaltungsfähigkeit. Demokratie und Rechtsstaatlichkeit sind voneinander ebenso wenig teilbar wie die Bedürfnisse des Menschen, auf die sie antworten.

II. Von den Häutungen der Gesellschaft zur Krise der repräsentativen Demokratie

Demokratie ist ein interdisziplinärer Verbundbegriff par excellence. Demokratiewissenschaften sind neben der Staats- und Völkerrechtslehre primär die Politikwissenschaft und die Ökonomik. Juridische ${ }^{13}$ und politikwissenschaftliche ${ }^{14}$ Zugänge überkreuzen sich in der Beschreibung des Volkes als „Konstitutions-, Legitimations- und Wirkeinheit“15 sowie in der

13 Zum rechtswissenschaftlichen Demokratiediskurs: J.P. Terhechte, Wandel klassischer Demokratievorstellungen in der Rechtswissenschaft - Europäisierung und Internationalisierung als Herausforderung in: H.M. Heinig/ders. (Hrsg.), Postnationale Demokratie, Postdemokratie, Neoetatismus, 2013, S. 193 (197 ff.).

14 A. Benz, Politikwissenschaftliche Diskurse über demokratisches Regieren in: H. Bauer/P.M. Huber/K.-P. Sommermann (Hrsg.), Demokratie in Europa, 2005, S. 253 (256 ff.). Benz fasst die im politikwissenschaftlichen Diskurs heraus gearbeiteten Funktionsbedingungen der Demokratie in folgenden Topoi zusammen: (1) Bestehen einer Kommunikationsgemeinschaft, (2) Minimum an Gemeinsamkeiten zwischen den Bürgern (,unkontroverser Sektor"), (3) ausgebildete Strukturen der Zivilgesellschaft. Siehe auch: K.-P. Sommermann, Demokratiekonzepte im Vergleich in: H. Bauer/P.M. Huber/ders. (Hrsg.) aaO, S. 191 (203).

15 R. Grawert, Staatsvolk und Staatsangehörigkeit in: J. Isensee/P. Kirchhof (Hrsg.), HStR II, 3. Auflage 2004, § 16, Rn. 27. 
Rekonstruktion der das Demokratieprinzip strukturierenden Schlüsselbegriffe: Souveränität, Legitimation, Repräsentation. ${ }^{16}$

In der Politiktheorie dominierte zunächst der Republikbegriff. ${ }^{17}$ „Demokratie“ schien dem Bürgertum, Trägerschicht der republikanischen Revolutionen in England, den USA und vor allem Frankreich, auf Grund ihres egalitären, auf das allgemeine Wahlrecht drängenden Charakters suspekt. ${ }^{18}$ Demokratische Ordnungsstrukturen sind entwicklungsoffen, ${ }^{19}$ weil sie auf dynamischen gesellschaftlichen Voraussetzungen aufbauen.

16 Freilich trifft eine Übersetzung interdisziplinärer Inklusion in methodische Beliebigkeit im rechtswissenschaftlichen Schrifttum auf Kritik. Exemplarisch: S. Unger, Das Verfassungsprinzip der Demokratie, 2008, S. 2: „Während der Phantasie der politischen Philosophie (...) keine Grenzen gesetzt sind (...), ist die Verfassungsrechtswissenschaft in ihren Antwortmöglichkeiten begrenzt: Wo die maßgeblichen Normen nicht hinführen, ist ihr der Weg versperrt". Siehe auch ders. aaO, S. 86 f. Unger formuliert aaO, S. 247 schließlich: „Thema des grundgesetzlichen Demokratiebegriffs ist (in Abgrenzung zu einem politikwissenschaftlichen - weiten - Demokratiebegriff) alleine die Legitimation politischer Herrschaft durch Inklusion der Beherrschten, nicht hingegen die inhaltliche Anleitung und Limitierung dieser Herrschaft“. Siehe dazu auch: E. Schmidt-Aßmann, Verwaltungslegitimaton als Rechtsbegriff, AöR 116 (1991), S. 329 (330): „Die Verbindungen zur politischen Ideengeschichte und zum gesamten Kanon der beteiligten Wissenschaften dürfen für den Rechtsbegriff nicht abreißen“. Mit anderem Fokus (Verbundenheit von Staat und Demokratie): U. Volkmann, Setzt Demokratie den Staat voraus?, AöR 127 (2002), S. 575 ff. Während Politikwissenschaft und Staatsphilosophie die Grenzen der Demokratie in freier Deliberation ausmessen, wobei der besondere Reiz dieses Vorgehens in der Kontrastierung der auf diese Weise gewonnenen Ergebnisse mit verfassungstextlichen Befunden bestehen kann, legt die strikt textgebundene staatsrechtliche Analyse die begriffliche Offenheit des Demokratieprinzips auf ein näher definiertes Konzept fest. Dies geschieht weniger durch persuasive Rhetorik als durch Verstetigung einer sich an plakativen Zuspitzungen orientierenden Rechtsprechung. Engführungen demokratietheoretischer Reflexionen sind deshalb im Staatsrecht unumgänglich.

17 K.-P. Sommermann, Demokratiekonzepte im Vergleich in: H. Bauer/P.M. Huber/ ders. (Hrsg.), Demokratie in Europa, 2005, S. 191 (199). Für Spanien: P. Cruz Villalón, Eine Anmerkung zur Demokratie in Spanien in: H. Bauer/P.M. Huber/K.-P. Sommermann (Hrsg.) aaO, S. 139 (140).

18 L. Heuschling, Krise der Demokratie und Krise der juristischen Demokratielehre in Frankreich in: H. Bauer/P.M. Huber/K.-P. Sommermann (Hrsg.), Demokratie in Europa, 2005, S. 33 (38).

19 K. Hesse, Verfassungsrecht der Bundesrepublik Deutschland, 20. Auflage 1995, Rn. 127 f.; G. Frankenberg, Vorsicht Demokratie! Kritik der juridischen Versicherung einer Gesellschaft gegen die Risiken der Selbstregierung in: Redaktion Kritische Justiz (Hrsg.), Demokratie und Grundgesetz, 2000, S. 177 ff. 
Demokratie lässt sich unterhalb einer hohen Abstraktionsebene kaum vergleichend analysieren, ${ }^{20}$ besitzt doch jeder demokratische Staat seine eigene politische Kultur. ${ }^{21}$ Während sich in der Bundesrepublik eine ausgefeilte, dennoch gegenüber wissenschaftlichen Innovationen offene Demokratiedogmatik entwickelt hat, dominiert in unseren Nachbarländern ein eher pragmatischer Umgang mit dem Demokratieprinzip. ${ }^{22}$ „Demokratie“ ist

20 M. Nettesheim, Demokratisierung der EU und Europäisierung der Demokratietheorie - Wechselwirkungen bei der Herausbildung eines europäischen Demokratieprinzips in: H. Bauer/P.M. Huber/K.-P. Sommermann (Hrsg.), Demokratie in Europa, 2005, S. 143 (162). K.-P. Sommermann, Demokratiekonzepte im Vergleich in: H. Bauer/P.M. Huber/ders. (Hrsg.), Demokratie in Europa, 2005, S. 191 (199) weist auf eine gemeineuropäische Einigkeit über Kernelemente des Demokratieprinzips hin: „Ausgehend von der Idee der freien Selbstbestimmung sich wechselseitig als gleichberechtigt anerkennender Bürger unter den Bedingungen gesellschaftlichen Zusammenlebens zählen dazu jedenfalls regelmäßige freie und gleiche Wahlen, eine auf Meinungs-, Presse-, Versammlungs- und Vereinigungsfreiheit basierende freie Meinungsbildung des Volkes, ein Mehrparteiensystem und die Verwirklichung des durch Minderheitenschutz gemäßigten Mehrheitsprinzips“".

21 H. Bauer, Demokratie in Europa - Einführende Problemskizze in: H. Bauer/P.M. Huber/K.-P. Sommermann (Hrsg.), Demokratie in Europa, 2005, S. 1 (2) mit Verweis auf Karl Doehrings Staatslehre. Siehe auch: M. G. Schmidt, Geschichtliche Entwicklungslinien der Demokratie in: H. Bauer/P.M.Huber/K.-P. Sommermann (Hrsg.) aaO, S. 21 (27 f.).

22 K.-P. Sommermann, Demokratiekonzepte im Vergleich in: H. Bauer/P.M. Huber/K.-P. Sommermann (Hrsg.), Demokratie in Europa, 2005, S. 191 (203); M. Jestaedt, Radien der Demokratie: Volksherrschaft, Betroffenenpartizipation oder plurale Legitimation? in: H.M. Heinig/J.P. Terhechte (Hrsg.), Postnationale Demokratie, Postdemokratie, Neoetatismus, 2013, S. 3 (7 f.). Als Beleg lässt sich für Frankreich L. Heuschling, Krise der Demokratie und der juristischen Demokratielehre in Frankreich in: H. Bauer/P.M. Huber/K.-P. Sommermann (Hrsg.), Demokratie in Europa, 2005, S. 33 (40) anführen: Heuschling merkt an, „dass der spezifische Inhalt des Begriffs Demokratie nur in der Verkopplung und/oder Konkurrenz mit anderen Termini (République, souveraineté nationale, liberté politique, État de droit, etc.) herausgeschält werden kann. Das Ideal einer scharfkantigen Abgrenzung des Sinninhaltes eines jeden Wortes (...) erscheint jedoch vom wissenschaftlichen Standpunkt aus nicht nur utopisch, sondern auch bis zu einem gewissen Grade unnütz. Rechtsdogmatische Falllösungen hängen selten von einem einzigen Wort (oder Prinzip) ab, sie bedingen meistens die Inbetrachtnahme der verschiedenen, formell mit gleichem Verfassungsrang ausgestatteten und inhaltlich miteinander verzahnten Grundprinzipien der politischen Ordnung (...)“. Für Großbritannien: G. Smith, The Structure of Democracy in the United Kingdom and Problems of Development in: H. Bauer/P.M.Huber/K.-P. Sommermann (Hrsg.) aaO, S. 69 (75). Für die Schweiz betont G. Biaggini, Ausgestaltung und Entwicklungsperspektiven des demokratischen Prinzips in der Schweiz in: H. Bauer/ 
der vielleicht missverständlichste Begriff der politischen Theorie. ${ }^{23}$ Seine schillernde Unbestimmtheit sperrt jeden Eigentlichkeitsdiskurs. Die jüngere Forschung ersinnt demnach Strategien, die assoziative Vielfalt in Mehrschichtenmodellen ${ }^{24}$ abzubilden. Mag über das Ungenügen eines formalistischen Ansatzes - die Demokratie ist kein Gegenstand der Arithmetik noch Einigkeit zu erzielen sein, so lassen sich beim Substanziellen Mehrdeutigkeiten nicht vermeiden. „Volksherrschaft" kann verstanden werden als

- Souveränitätsprinzip: Verteilung politischer Macht zu Händen des Volkes, wobei zwischen dem Volk als Träger der Staatsgewalt und dem Aktivdemos unterschieden wird;

- Identitätsprinzip: Identität der Regierenden mit den Regierten, ${ }^{25} \mathrm{Ga}$ rantie subjektiver Freiheit im und Versöhnung des Individuums mit dem Kollektiv;

- Steuerungs- und Organisationsprinzip: ${ }^{26}$ Verfahrenskodex der Republik, wonach Freiheit und Gleichheit mit dem Ziel der Programm- und Elitenauswahl in Einklang zu bringen sind;

P.M.Huber/K.-P. Sommermann (Hrsg.) aaO, S. 107 (110) ebenfalls den eher „beiläufigen“ Charakter der Evokation des Demokratieprinzips in der juristischen Diskussion: „Hier kommt eine gewisse Abneigung der Schweizerinnen und Schweizer gegenüber (allzu) abstrakten 'Prinzipien' zum Ausdruck. Dass und inwieweit die Schweiz eine Demokratie ist, soll sich aus möglichst konkret gefassten Verfassungsbestimmungen ergeben, welche die einzelnen Instrumente der Mitentscheidung und der demokratischen Kontrolle möglichst klar regeln und verfassungsrechtlich absichern, nicht aus einem 'Verfassungsprinzip'“. Zu Spanien: P. Cruz Villalón, Eine Anmerkung zur Demokratie in Spanien in: H. Bauer/P.M.Huber/K.P. Sommermann (Hrsg.) aaO, S. 139 (140).

23 Zur thematischen Unschärfe des Demokratieprinzip: S. Unger, Das Verfassungsprinzip der Demokratie, 2008, S. 85 m.w.N.

24 Beispielhaft: M. Jestaedt, Radien der Demokratie: Volksherrschaft, Betroffenenpartizipation oder plurale Legitimation? in: H.M. Heinig/J.P. Terhechte (Hrsg.), Postnationale Demokratie, Postdemokratie, Neoetatismus, 2013, S. 3 ff.

25 C. Schmitt, Verfassungslehre, 3. Auflage 1957, S. 234 ff.

26 T. Blanke, Funktionale Selbstverwaltung und Demokratieprinzip in: Redaktion Kritische Justiz (Hrsg.), Demokratie und Grundgesetz, 2000, S. 32 (34). Am Beispiel der Entscheidung des BVerfG zum Mitbestimmungsgesetz des Landes Schleswig-Holstein (BVerfGE 93, 37) erläutert Blanke aaO, S. 38 ff. die demokratietheoretischen Implikationen einer an Modellen hierarchischer Exekutivsteuerung ausgerichteten Verwaltungsorganisation. 
- Friedensprinzip, wobei die Chance zum friedlichen periodischen Regierungswechsel mindestens ebenso bedeutsam ist wie die Garantie eines öffentlichen Meinungswettstreits ohne Repressalien und Partizipationshürden.

Begriffliche Unschärfen beschwören Thesen vom „Wandel der Demokratie" herauf. In immer exotischeren Neologismen ${ }^{27}$ weist die Wissenschaft ihre Sprachlosigkeit vor den Häutungen der Gesellschaft ${ }^{28}$ aus. Betrifft Demokratie nur die unter Hoheitlichkeitsvorbehalt (Art. 33 IV GG) stehende Staatsgewalt ${ }^{29}$ oder beeinflusst sie die gesamte Staatsorganisation $^{30}$ ? Muss sie vielleicht sogar darüber hinaus - wie Rundfunk- und Pressewesen belegen - als ein Funktionselement gesellschaftlicher Selbstregulierung aufgefasst werden? ${ }^{31}$ Sind nicht auch die Sitzungssäle des Bundes-

27 Eine kleine „Sammlung“ findet sich bei: D. Michelson/F. Walter, Unpolitische Demokratie. Zur Krise der Repräsentation, 2013, S. 111.

28 I. Blühdorn, Simulative Demokratie, 2013, S. 159, 203 schreibt zutreffend vom „Formwandel“ der Demokratie bzw. der demokratischen Repräsentation.

$29 \mathrm{Zu}$ dieser Auslegungsmöglichkeit des Begriffes „Staatsgewalt“ in Art. 20 II 1 GG: E. Schmidt-Aßmann, Verwaltungslegitimation als Rechtsbegriff, AöR 116 (1991), S. 329 (339).

30 So BVerfGE 47, 253 (273); 77, 1 (40).

31 Unbesehen der politikwissenschaftlichen Diskussion - Demokratie als Gesellschaftsmodell bzw. „Lebensform“ - sprechen aus staatsrechtlicher Perspektive gegen eine „Sozialisierung“ des Demokratieprinzips Art. 21, 9 III GG. Die genannten Vorschriften nehmen mit politischen Parteien, Gewerkschaften und Arbeitgeberverbänden Vereinigungen, die für die gesellschaftliche Selbstorganisation von wesentlicher Bedeutung sind, vom Anwendungsbereich des Demokratiegebots (Art. 20 I, II GG) aus. Es ist gerade dieser Gesichtspunkt, der die politische mit der koalitionären Selbstregulierung verbindet. Das Grundgesetz stellt damit klar, dass sich auf dem Boden des Verfassungsrechts weder politische Parteien noch Interessenverbände des Wirtschaftslebens auf einen legitimatorischen „Vorschuss“ gegenüber dem Bürger, gar auf einen Status als „Teilvolk“ berufen können. Aufschlussreich ist insoweit die Formulierung des Art 21 I 2 GG, wonach die innere Ordnung politischer Parteien demokratischen Grundsätzen „entsprechen“ muss, jedoch - die Parteibasis ist nicht das „Volk“ im Sinne des Art. 20 GG - nicht „,demokratisch" stricto sensu sein kann. Verfassungsrechtsdogmatisch ist mithin eine Ausdehnung demokratieprinzipieller Vorgaben auf die gesellschaftliche Mitbestimmung fragwürdig (in der Konsequenz auch: BVerfGE 93, 37). So auch: E. Schmidt-Aßmann, Verwaltungslegitimation als Rechtsbegriff, AöR 116 (1991), S. 329 (347). Siehe ferner: T. Groß, Grundlinien einer pluralistischen Interpretation des Demokratieprinzips in: Redaktion Kritische Justiz (Hrsg.), Demokratie und Grundgesetz, 2000, S. 93 (100); R. Herzog in: T. Maunz/G. Dürig (Hrsg.), Grundgesetz-Kommentar, Art. 20 II, Rn. 115; P.M. Huber, Demokratie in Europa - Zu- 
verfassungsgerichts, des Gerichtshofs der Europäischen Union und des Europäischen Gerichtshofs für Menschenrechte Orte der Demokratie? ${ }^{32}$ Und schließlich: Darf man Defizite repräsentativ-parlamentarischer Verfahren mit Vorzügen administrativer Partizipation saldieren, mithin gegen die parlamentarische Öffentlichkeit eine mehr informale Publizität ins Spiel bringen? Mit der demokratischen Repräsentation ist die Art und Weise, wie das Volk seinen Willen artikuliert, angesprochen. Dieser Problembezug führt mitten hinein in Kontroversen um die repräsentativ-parlamentarische Regierungsform, anhand derer sich unterschiedliche demokratietheoretische Ansätze erschließen. ${ }^{33}$ Repräsentation ist auf mittlerer

sammenfassung und Ausblick in: H. Bauer/ders./K.-P. Sommermann (Hrsg.), Demokratie in Europa, 2005, S. 491 (493).

32 So die These von P. Rosanvallon, Demokratische Legitimität, BPB-Sonderausgabe 2013, S. 170 ff., wonach der Verfassungsgerichtsbarkeit (präziser: der von ihr ausgeübten kassatorischen Normenkontrolle) eine spezifische demokratische Legitimität, die Legitimität der Reflexion, zukommt. In der Politikwissenschaft wird die demokratische (bzw. demokratietheoretische) Relevanz der Verfassungsgerichtsbarkeit stärker reflektiert als in der Staatsrechtslehre. Siehe dazu: D. Michelson/F. Walter, Unpolitische Demokratie. Zur Krise der Repräsentation, 2013, S. 42 m.w.N. Siehe auch bei Rosanvallon aaO, S. 171 das Zitat von Benjamin Constant, der in der Verfassungsgerichtsbarkeit eine „bewahrende Gewalt“ (pouvoir préservateur) sieht. Rosanvallon wendet sich aaO, S. 171 explizit gegen Hans Kelsens Theorie der Verfassungsgerichtsbarkeit, deren Normenkontrollauftrag sich als negative Gesetzgebung verstehe, deren Sinn sich in der Affirmation einer juridischen Normenhierarchie erschöpfe und die daher für die Bereitstellung demokratischer Legitimation nicht fruchtbar zu machen sei. Siehe auch: L. Heuschling, Krise der Demokratie und der juristischen Demokratielehre in Frankreich in: H. Bauer/P.M. Huber/K.-P. Sommermann (Hrsg.), Demokratie in Europa, 2005, S. 33 (62) mit Bezug auf Dominique Rousseau. Kritisch, mit Blick auf die „counter-majoritarian difficulty": A.M. Bickel, The Least Dangerous Branch. The Supreme Court at the Bar of Politics, Neuausgabe 1986 (1962), S. 16 ff.

33 Freilich bleibt dabei ein für die zeitgenössische Diskussion bedeutsamer Strang der Demokratiekritik: die mit der Staatsaufgabenlehre in Zusammenhang stehende Demaskierung von „Steuerungsdefiziten“ wahlweise der Gesetzgebung oder ihrer exekutiven Umsetzung außer Betracht. Zur Verknüpfung steuerungs- und demokratietheoretischer Überlegungen: C. Hohmann-Dennhardt, Schranken des Demokratieprinzips in: Redaktion Kritische Justiz (Hrsg.), Demokratie und Grundgesetz, 2000, S. 102 (107). Hiernach resultiert der Bedarf nach Vereinbarung demokratischer Repräsentation mit plebiszitär-partizipativen und sonstigen Legitimationssurrogaten daraus, „dass der demokratische Staat, der dem Wohl aller und der Wahrung der Grundrechte seiner Bürger verpflichtet ist, mit seinen klassischen Handlungsformen und -instrumentarien, wie auch mit seinem Aktionsradius nicht mehr mit der dynamischen Entwicklung der in die Globalisierung entlassenen 
Ebene zwischen Staatstheorie und juristischer Dogmatik angesiedelt. Repräsentationstheorien übersetzen die grundrechtlich-demokratische Freiheitsidee in die Dogmatik des verfassungsrechtlichen Demokratiegebots, legen unter der Oberfläche der rudimentären, ${ }^{34}$ in Art. 20 I, II, 21 I, II, 38 I, II GG angelegten Verfassungsstrukturbestimmungen Staatsziele und Organisationsmodelle frei. Sie ermöglichen somit eine Relationierung von vorverständnisoffenen (einer ,juridischen Deliberation“ zugänglichen) Elementen der Verfassungsauslegung und ihren bedeutungsfesten Ausgangspunkten. ${ }^{35}$ Die repräsentative Demokratie versöhnt den Anspruch jedes einzelnen auf gleiche politische Einflussnahme ${ }^{36}$ mit dem Gesetz der kleinen Zahl. ${ }^{37}$ Auf Grund der Entfernung ihres Legitimationsziels - die treuhänderische Übertragung der Regierungsgewalt an ein Repräsentativorgan - vom Einzelfall sieht sich parlamentarische Repräsentation allerdings in ungleich größerem Maße Rechtfertigungsanfragen ausgesetzt als ihre plebiszitäre (besser: referendumsdemokratische) Schwester. ${ }^{38}$ Die Mehrdeutigkeit des Demokratiebegriffs gestattet ein Spiel mit Assoziationen, ein Hin- und Herwenden der Begrifflichkeit zwischen Verfassungs-

Wirtschaft, der Wissensproduktion und -vermarktung (...) Schritt hält und damit rapide Steuerungsfähigkeit innerhalb seines Verantwortungsbereichs einbüßt".

34 K. Hesse, Grundzüge des Verfassungsrechts der Bundesrepublik Deutschland, 20. Auflage 1995, Rn. 129.

35 E. Schmidt-Aßmann, Verwaltungslegitimation als Rechtsbegriff, AöR 116 (1991), S. 329 (334 f.) entwickelt komplementär zu dem von mir vertretenen Ansatz ein Modell von „Wirkungsstufen“ des grundgesetzlichen Demokratiegebots.

36 P. Badura, Die parlamentarische Demokratie in: J. Isensee/P. Kirchhof (Hrsg.), HStR II, 3. Auflage 2004, § 25, Rn. $31 \mathrm{f}$.

37 H. Heller, Politische Demokratie und soziale Homogenität in: U. Matz (Hrsg.), Grundprobleme der Demokratie, 1973, S. 7 (10).

38 E.-W. Böckenförde, Demokratische Willensbildung und Repräsentation in: J. Isensee/P. Kirchhof (Hrsg.), HStR III, 3. Auflage 2005, § 34, Rn. 1. Andere kritisieren die „versteckte Repräsentationsstruktur“ der plebiszitären Demokratie (S. Unger, Das Verfassungsprinzip der Demokratie, 2008, S. 63 mit Fn. 258, dort Nachweise zum Streitstand). Oft mischen sich in das Hohelied von der plebiszitären Demokratie Missklänge einer überzogenen Skepsis gegen die Institutionen der repräsentativen Demokratie, insbesondere gegen politische Parteien. $\mathrm{Zu}$ den Wurzeln derartiger Kritik in der Französischen Revolution: P. Rosanvallon, Demokratische Legitimität, BPB-Sonderausgabe 2013, S. 153. 
prinzip und Regierungsform, ${ }^{39}$ Herrschafts- und Lebensmetaphorik. ${ }^{40}$ In diesem assoziativen Feld gilt Repräsentation dem einen als ,geistiges Feigenblatt" für Klassenkampf und Kolonialismus, ${ }^{41}$ dem anderen als Essenz gleicher, demokratischer Freiheit. ${ }^{42}$ Konstanten der Auseinandersetzungen um das Demokratiegebot des Grundgesetzes sind

- dessen Bezugspunkte zu einem pluralistischen Gemeinwohlverständnis, ${ }^{43}$

- Forderungen nach Mitentscheidung des Bürgers bei der Ausübung von Staatsgewalt, ${ }^{44}$

39 G. Agamben, Einleitende Bemerkungen zum Begriff der Demokratie in: ders. u.a., Demokratie? Eine Debatte, 2012, S. 9 (9); ebenso: J.-L. Nancy, Begrenzte oder unendliche Demokratie in: Agamben aaO, S. 72 (72): „Letztlich kann 'Demokratie' alles bedeuten - Politik, Ethik, Recht, Zivilisation - und bedeutet folglich überhaupt nichts“; K. Ross, Demokratie zu verkaufen in: Agamben aaO, S. 96 (96). W. Brown, Wir sind jetzt alle Demokraten ... in: Agamben aaO, S. 55 (56 f.) sekundiert: Demokratie sei ein ,unvollendetes Prinzip - sie legt weder genau fest, welche Gewalten unter uns geteilt werden müssen, damit die Volksherrschaft ausgeübt werden kann, noch wie diese Herrschaft organisiert sein muss, noch durch welche Institutionen oder zusätzlichen Bedingungen sie ermöglicht oder gesichert wird“.

40 M. Nettesheim, Demokratisierung der EU und Europäisierung der Demokratietheorie - Wechselwirkungen bei der Herausbildung eines europäischen Demokratieprinzips in: H. Bauer/P.M. Huber/K.-P. Sommermann (Hrsg.), Demokratie in Europa, 2005, S. 143 (150). Siehe auch: I. Blühdorn, Simulative Demokratie, 2013, S. 83 mit Verweis auf Benjamin Barber.

41 K. Ross, Demokratie zu verkaufen in: G. Agamben u.a., Demokratie? Eine Debatte, 2012, S. 96 (111).

42 K.-P. Sommermann, Demokratiekonzepte im Vergleich in: H. Bauer/P.M. Huber/ ders. (Hrsg.), Demokratie in Europa, 2005, S. 191 (211): Das Repräsentationsprinzip im Verbund mit der Gewaltenteilung als „Voraussetzung für ein `government of laws and not of men'“, wobei eben „government" rechtsstaatliche Freiheit und staatsbürgerliche Gleichheit miteinander versöhnt.

43 Dieses stößt freilich in der Politikwissenschaft mitunter auf polemische Kritik. Siehe bspw. das Zitat von Elmer Eric Schattschneider aus dem Jahr 1960: „Das Problem bei dem himmlischen Bild, das die Pluralisten werfen, besteht darin, dass der Chor der Engel mit einem starken Oberklassenakzent singt" (nach: I. Blühdorn, Simulative Demokratie, 2013, S. 97 f.).

44 R. Walter/W. Schmitt Glaeser, Partizipation an Verwaltungsentscheidungen, VVDStRL 31 (1973), S. 147 ff., 179 ff. T. Groß, Grundlinien einer pluralistischen Interpretation des Demokratieprinzips in: Redaktion Kritische Justiz (Hrsg.), Demokratie und Grundgesetz, 2000, S. 93 (98) deutet die „pluralistische“ Variante des Demokratieprinzips zutreffend als Rechtfertigung „verschiedene(r) Gestaltungsformen der politischen Willensbildung (...) zur Erweiterung individueller Selbstbestimmung durch Mitwirkung“. Allgemein zu „Rahmenbedingungen (..), 
- die Abgrenzung repräsentativer zu plebiszitären Demokratievarianten,

- die Voraussetzungen effektiver demokratischer Legitimation,

- formale und materiale Aspekte des Demokratiebegriffs. ${ }^{45}$

Im aktuellen staatsrechtlichen Problemfokus stehen - mit starkem Bezug $\mathrm{zu}$ Verwaltungsrecht und Verwaltungsreformen, zum Gesetzmäßigkeitsprinzip als Konsequenz sachlich-inhaltlicher Legitimation - ministerialfreie Räume und verselbständigte Verwaltungseinheiten, ${ }^{46}$ funktionale Selbstverwaltung ${ }^{47}$ und autonome Legitimation, ${ }^{48}$ Parlaments- und Wesentlichkeitsvorbehalt, ${ }^{49}$ privatrechtsförmige Verwaltung ${ }^{50}$ sowie allgemein die demokratische Bindung der dritten Gewalt, ${ }^{51}$ insbesondere an der Grenze zwischen Gesetzesauslegung und richterlicher Rechtsfortbildung. ${ }^{52}$ Die genannten Diskussionspunkte lassen sich sämtlich auf die Repräsentationslehre zurückführen. In diesem Lichte erscheinen sie als pathologische Fälle einer auf die Einsetzung von Amtsträgern und behördliche Einwirkungseffizienz zugeschnittenen Parlamentarismuskonzeption. Sie fügen sich zwanglos in eine Verfallserzählung ein, deren institutionen-

die Legitimationsdefizite der Demokratie zu reduzieren helfen“: C. HohmannDennhardt, Schranken des Demokratieprinzips in: Redaktion Kritische Justiz (Hrsg.) aaO, S. 102 (109).

45 M. Kotzur, Die Demokratiedebatte in der deutschen Verfassungsrechtslehre in: H. Bauer/P.M. Huber/K.-P. Sommermann (Hrsg.), Demokratie in Europa, 2005, S. 351 (367 ff.).

46 W. Hoffmann-Riem, Eigenständigkeit der Verwaltung in: ders./E. Schmidt-Aßmann/A. Voßkuhle (Hrsg.), GVwR I, 2. Auflage 2012, Rn. 53 ff.

47 H.-H. Trute, Die demokratische Legitimation der Verwaltung in: W. HoffmannRiem/E. Schmidt-Aßmann/A. Voßkuhle (Hrsg.), GVwR I, 2. Auflage 2012, §6, Rn. 20, 48, 82 ff.

48 E. Schmidt-Aßmann, Verwaltungslegitimation als Rechtsbegriff, AöR 116 (1991), S. 329 (344).

49 F. Reimer, Das Parlamentsgesetz als Steuerungsmittel und Kontrollmaßstab in: W. Hoffmann-Riem/E. Schmidt-Aßmann/A. Voßkuhle (Hrsg.), GVwR I, 2. Auflage 2012, § 9, Rn. $47 \mathrm{ff}$.

50 M. Burgi, Rechtsregime in: W. Hoffmann-Riem/E. Schmidt-Aßmann/A. Voßkuhle (Hrsg.), GVwR I, 2. Auflage 2012, § 18, Rn. 56 ff.; M. Heintzen/A. Voßkuhle, Beteiligung Privater an der Wahrnehmung öffentlicher Aufgaben und staatliche Verantwortung, VVDStRL 62 (2003), S. 221 ff., 266 ff.; E. Schmidt-Aßmann, Verwaltungslegitimation als Rechtsbegriff, AöR 116 (1991), S. 329 (346 ff.).

51 G. Roellecke/C. Starck, Die Bindung des Richters an Gesetz und Verfassung, VVDStRL 34 (1976) S. 7 ff., 43 ff.

52 H. Bauer, Demokratie in Europa - Einführende Problemskizze in: ders./P.M. Huber/K.-P. Sommermann (Hrsg.), Demokratie in Europa, 2005, S. 1 (3, 12 ff.). 
theoretische Variante beim Parlament als Zentrum des Politischen angesiedelt ist, während eine steuerungstheoretisch grundierte Alternativfassung von der sinkenden Relevanz des parlamentarischen Gesetzes handelt. Hatten zunächst noch Wettbewerbstheorien ein der politischen Ökonomie entlehntes Demokratieverständnis ${ }^{53}$ geprägt $^{54}$ (wobei „Wettbewerb“ sowohl als Konsequenz der Gleichheit der demokratischen Subjekte wie auch als Instrument einer Bestenauslese an potentiellen Amtsträgern verstanden werden kann), ${ }^{55}$ dominieren seit Ende der neunziger Jahre Thesen von einer ,postfordistischen Politik" 56 oder - mit stärkerem Bezug zur politischen Form - „Postdemokratie“. ${ }^{57}$ Dieser aus dem französisch- und englischsprachigen Raum importierte Streit verschmilzt hierzulande mit dem Anliegen einer „neue[n] Politie“, 58 bildet die Prognosebasis einer „Rück-

53 Dazu: G. Kirsch, Neue Politische Ökonomie, 5. Auflage 2004, S. 201 ff. Klassisch: A. Downs, Ökonomische Theorie der Demokratie, 1968; J.M. Buchanan, Die Grenzen der Freiheit zwischen Anarchie und Leviathan, 1984; R.A. Posner, Pragmatism and Democracy, 2003.

54 Diese verstehen sich durchaus nicht nur als Metaphern, sondern als ,,analytische Kategorie, die es erlaubt, Erkenntnisse der Ökonomie für das bessere Verständnis und die Optimierung politischer Entscheidungsprozesse fruchtbar zu machen" (A. Hatje, Demokratie als Wettbewerbsordnung, VVDStRL 69 (2010), S. 135 (143)). Als solche umschreiben die Begriffe der Wettbewerbstheorie „ein ganz allgemein bestehendes soziales, deshalb nie ideales Beziehungsmuster" (M. Kotzur, Demokratie als Wettbewerbsordnung, VVDStRL 69 (2010), S. 173 (183)). Kotzur macht aaO, S. 188 auf den stärker werbenden Charakter des politischen Wettbewerbs aufmerksam, auf den hin die übrigen Wettbewerbsfunktionen ausgerichtet sind.

55 P. Rosanvallon, Demokratische Legitimität, BPB-Sonderausgabe 2013, S. 72.

56 I. Blühdorn, Simulative Demokratie, 2013, S. 69.

57 J. Rancière, Demokratie und Postdemokratie in: ders./A. Badiou (Hrsg.), Politik der Wahrheit, 1996, S. 119 ff.; S. Wolin, Tocqueville Between Two Worlds. The Making of a Political and Theoretical Life, 2001, S. 561 ff.; C. Crouch, Postdemokratie, 2008. Kritik bei: I. Blühdorn, Simulative Demokratie, 2013, S. 116 ff. (besonders S. 116: „Postdemokratie“ als „Kampfbegriff“). Analyse der postdemokratischen Konstellation bei: G. Hermet, Willkommen im nachdemokratischen Zeitalter, Internationale Politik 63/4, S. 108 ff. Eine überraschende Parallele des Postdemokratiediskurses zu Oswald Spengler zieht J.P. Terhechte, Wandel klassischer Demokratievorstellungen in der Rechtswissenschaft - Europäisierung und Internationalisierung als Herausforderung in: H.M. Heinig/ders. (Hrsg.), Postnationale Demokratie, Postdemokratie, Neoetatismus, 2013, S. 193 (206 mit Fn. 61).

58 D. Sternberger, Die neue Politie. Vorschläge zu einer Revision der Lehre vom Verfassungsstaat, JöR n.F. 33 (1984), S. 1 ff. 
kehr der Demokratiefrage“".59 Zwar gibt es auch affirmative Modelle der repräsentativen Demokratie, ${ }^{60}$ doch es überwiegt die Skandalisierung der vermeintlichen Macht der Medienbranche zum Agenda Setting ${ }^{61}$ und der angeblichen Überfülle lebensweltlicher Komplexität außerhalb der demokratischen Institutionen. Mancher Autor mischt in diesen Cocktail einen Schuss Gesellschaftskritik hinein. So tritt auf der post-demokratischen Bühne die Masse auf, die in der Demokratie nichts anderes zu sehen vermöge als einen Selbstbedienungsbetrieb und eben dadurch die Wurzeln des auf gleicher Freiheit gründenden Gemeinwesens vergifte. ${ }^{62}$ Zuzugeben ist, dass Jacques Rancière, Sheldon Wolin und Colin Crouch - Hauptpropagandisten der Postdemokratie - mit ihren Überlegungen einen Nerv der Nach-Wende-Zeit trafen. Immer neue Beiträge zu „Bedrohungen der Demokratie“63 variieren die seit Jürgen Habermas' „Legitimationsprobleme im Spätkapitalismus“ (1973) intonierte Melodie von der technizistischen Selbstreferentialität einer expertokratischen Ordnung. Zuletzt kreist die Debatte unter dem Eindruck der Finanz- und Haushaltskrise im Euroraum um das Verhältnis von Demokratie und „neoliberaler“ Netzwerkgesellschaft, um die Entlarvung der Globalisierung als politische Ideologie, ${ }^{64}$ um demokratische Räume jenseits des Staates. ${ }^{65}$ Teilweise schließt man

59 M. Zürn, Die Rückkehr der Demokratiefrage. Perspektiven demokratischen Regierens und die Rolle der Politikwissenschaft in: Blätter für deutsche und internationale Politik 56/6 (2001), S. $63 \mathrm{ff}$.

60 S. Augsberg, Gesellschaftlicher Wandel und Demokratie: Die Leistungsfähigkeit der parlamentarischen Demokratie unter Bedingungen komplexer Gesellschaften in: H.M. Heinig/J.P. Terhechte (Hrsg.), Postnationale Demokratie, Postdemokratie, Neoetatismus, 2013, S. 27 (37 ff.).

61 E.-W. Böckenförde, Demokratische Willensbildung und Repräsentation in: J. Isensee/P. Kirchhof (Hrsg.), HStR III, 3. Auflage 2005, § 34, Rn. $36 \mathrm{ff.}$

62 A. Badiou, Das demokratische Wahrzeichen in: G. Agamben u.a., Demokratie? Eine Debatte, 2012, S. 13 (19).

63 Siehe beispielsweise: A. Brodocz/M. Llanque/G.S. Schaal (Hrsg.), Bedrohungen der Demokratie, 2008; S. Braun/A. Geisler (Hrsg.), Die verstimmte Demokratie. Moderne Volksherrschaft zwischen Aufbruch und Frustration, 2012. Affirmativ: D. Jörke, Auf dem Weg zur Postdemokratie, Leviathan 33 (2005), S. 482 ff. Skeptisch: C. Mouffe, „Postdemokratie“ und die zunehmende Entpolitisierung, APuZ 1-2/2011, S. 3 (12).

64 H. Albert, Ökonomische Theorie als politische Ideologie: Das ökonomische Argument in der ordnungspolitischen Debatte, 2009.

65 Klassisch: T.M. Franck, The Emerging Right to Democratic Governance, AJIL 86 (1992), S. $46 \mathrm{ff}$. 
von den Schwächen des Parlamentarismus ${ }^{66}$ auf eine Dysfunktionalität demokratischer Staatsorganisation. Die post-demokratische Erzählung verheißt der repräsentativen Demokratie nichts Gutes. Repräsentation wird zur Schimäre, wo der Begüterte bestellt, was er durch Parteispenden und Lobbyarbeit bezahlt hat. Die parlamentarische Debatte ist Spiegelfechterei, wenn die Abgeordneten nicht (mehr) über Positionen, sondern allenfalls (noch) über Personalien abstimmen. Wo postdemokratischer Pessimismus die Oberhand gewinnt, sucht sich das Volk neue Wege, um seine Stimme zu erheben. Die „Perspektiven der repräsentativen Demokratie“ hängen allerdings nicht davon $a b$, ob sich postmodernistische Abgesänge ihre Wirklichkeit selbst zu schaffen vermögen. Demokratische Repräsentation ist Nomos; ihre Verstehensfäden sind aus Normen gewirkt. Im Rahmen einer rechtswissenschaftlichen Analyse ist mithin zu zeigen, wie sich die postdemokratische Konstellation im Recht widerspiegelt. Sedes materiae ist das Demokratiegebot des Grundgesetzes.

\section{Repräsentative Demokratie - postdemokratisch gewendet}

Mit Peter Häberle ist Demokratie die organisatorische Konsequenz aus der Menschenwürde. ${ }^{67}$ Das Volk konstituiert sich im Spannungsfeld von politischer Imagination und Herrschaftspraxis ${ }^{68}$ als staatsrechtliches Zurechnungssubjekt, als „Handlungs- und Wirkeinheit“ ${ }^{69}$ Eine substanzontologische Definition des Volkes wird ebenso zurück gewiesen wie eine radikalidealistische Perspektive, die im Demos nurmehr eine regulative Idee erkennen will. ${ }^{70}$ Im Grundgesetz kommt die der Demokratie implizite Gestaltungsfreiheit am deutlichsten in Art. 38 III GG zum Vorschein. Das Wahlsystem steht nicht im Kleingedruckten des Gesellschaftsvertrags, sondern entscheidet über die Form der politischen Ordnung. Mehrheits-

66 M. Brenner, Das Prinzip Parlamentarismus in: J. Isensee/P. Kirchhof (Hrsg.), HStR III, 3. Auflage 2005, $\S 44$, Rn. 55 ff.

67 P. Häberle, Die Menschenwürde als Grundlage der staatlichen Gemeinschaft in: J. Isensee/P. Kirchhof (Hrsg.), HStR II, 3. Auflage 2004, § 22, Rn. 67.

68 P. Badura, Die parlamentarische Demokratie in: J. Isensee/P. Kirchhof (Hrsg.), HStR II, 3. Auflage 2004, § 25, Rn. 28.

69 E.-W. Böckenförde, Demokratische Willensbildung und Repräsentation in: J. Isensee/P. Kirchhof (Hrsg.), HStR III, 3. Auflage 2005, § 34, Rn. 9.

70 E.-W. Böckenförde, Demokratische Willensbildung und Repräsentation in: J. Isensee/P. Kirchhof (Hrsg.), HStR III, 3. Auflage 2005, § 34, Rn. 31 ff. 
oder Verhältniswahl samt ihren Zwischenformen sind keine beliebigen, da austauschbaren Platzhalter in einer variablen Geometrie. Vielmehr stützen sie jeweils unterschiedliche Varianten der Volksherrschaft. Eingedenk der Tragweite der Elektoralprämissen hat der Verfassungsgeber mit Art. 38 III GG Weitblick bewiesen. In Konsequenz der mit Art. 20 I GG weit gefassten Prinzipienentscheidung belässt er wesentliche Konkretisierungsvorbehalte in der Kompetenz des parlamentarischen Gesetzgebers. Es täte sich anderenfalls ein Wertungswiderspruch auf. Wer an der einen Stelle mit der Prinzipialisierung der Demokratie (Art. 20 I GG) die Evolutivität des politischen Systems betont, kann nicht an anderer Stelle die Entscheidung über die Regeneration dieses Systems - Bedingungen und Verfahren der Wahl - durch konstitutionelle Verregelung einfrieren. Indem Art. 38 III GG das Wahlrecht der politischen Opportunität öffnet, wird eine große Bandbreite an demokratischen Formen auf den Boden der Verfassung gestellt. Auf der Grundlage des verfassungsfesten repräsentativen Mandats (Art. 38 I 2 GG) sind Kombinationen der Mehrheits- mit der Verhältniswahl, der repräsentativen mit der plebiszitären Demokratie verfassungsrechtlich statthaft, solange man urteilen kann: „The representatives act not as agents of the people but simply instead of them". ${ }^{71}$ Somit ist sichergestellt, dass ein wachsender Bedarf nach politischer Mitsprache in die Textur des Staatsrechts eingewoben werden kann. Von wissenschaftlicher Unbestrittenheit weit entfernt und dennoch allgemein akzeptiert, hat der Bundesgesetzgeber das Wahlrecht der Bundesrepublik Deutschland auf die Grundsätze „einer mit der Personenwahl verbundenen Verhältniswahl“ (§ 1 I 2 BWahlG) festgelegt. Die Grundentscheidung des deutschen Gesetzgebers für die repräsentative Demokratie ist somit doppelt abgesichert: verfassungsrechtlich durch Art. 38 I 2 i.V.m. Art. 20 II 2 (,Wahlen“) GG sowie einfach-gesetzlich. „Repräsentation“ ist mit den Worten Hanna Pitkins ,the making present in some sense of something which is nevertheless not present literally or in fact“. ${ }^{72}$ Anders gesagt: „Repräsentation“ ist die Umsetzung der gegen politische Akteure erhobenen Forderung nach Responsivität („Abbildung der Werte und Interessen der Bürger durch ihre Repräsentanten" $)^{73}$ in ein Verfahren der Verständigung über Problembe-

71 H. Pitkin, Representation and Democracy: Uneasy Alliance, Scandinavian Political Studies 27 (2004), S. 335 (339).

72 H. Pitkin, The Concept of Representation, 1967, S. 8 f.

73 I. Blühdorn, Simulative Demokratie, 2013, S. 208. 
schreibungen und Wertorientierungen. ${ }^{74}$ Argumente für das Repräsentationsprinzip sind

- die mangelnde Praktikabilität deliberativer Aushandlungsprozesse in bevölkerungsmäßig größeren politischen Einheiten; ${ }^{75}$

- die Komplexität der politischen Sachentscheidungen;

- der mangelnde Wille oder das mangelnde Verständnis mancher Bürger, an politischen Angelegenheiten teilzunehmen;

- die Angewiesenheit eines politischen Gemeinwesens auf Repräsentativorgane, um zu einer Handlungseinheit zu gelangen. ${ }^{76}$

Ausgehend von einer kritischen Sichtweise auf die oligarchische Grundierung der repräsentativen Demokratie, ${ }^{77}$ bewegen uns die von der Postdemokratie-These ausgehenden Analysemuster zum Nachdenken darüber, was es bedeutet, dass die Staatsgewalt ${ }^{78}$ vom Volke ausgeht, jedoch nicht von ihm ausgeübt wird. ${ }^{79}$ Sie erinnern uns an die Konfusion zweier Demokratiebegriffe: „Demokratie“ als Regierungsform und als gesellschaftlicher Status. ${ }^{80}$ Sie setzen diese Doppelwertigkeit des Demoskonzepts (verstanden zugleich als in der „Gesamtheit der Deutschen“ idealisiertes

74 I. Blühdorn, Simulative Demokratie, 2013, S. 208 f.

75 Kritisch: H. Münkler, Regierungsversagen, Staatsversagen und die Krise der Demokratie, Berliner Republik 5/2010, S. 49 (51) mit der Warnung, dass sich die deliberative unter der Hand in eine dezisive Demokratie verwandeln könnte. Siehe auch I. Blühdorn, Simulative Demokratie, 2013, S. 104: „Was sich als herrschaftsfreier Diskurs und Kraft des besseren Arguments darstellt, ist in Wahrheit nicht viel mehr als die erklärende Vermittlung des vermeintlich Alternativlosen und des im Sinne der gesellschaftlichen Elite Vernünftigen“.

76 K.-P. Sommermann, Demokratiekonzepte im Vergleich in: H. Bauer/P.M. Huber/ ders., Demokratie in Europa, 2005, S. 191 (209).

77 K. Ross, Demokratie zu verkaufen in: G. Agamben u.a., Demokratie? Eine Debatte, 2012, S. 96 (114).

78 BVerfGE 93, 37 (68); 83, 60 (73 f.).

79 P. Badura, Die parlamentarische Demokratie in: J. Isensee/P. Kirchhof (Hrsg.), HStR II, 3. Auflage 2004, § 25, Rn. 34.

80 In letzterem Sinne ist Demokratie - nach Ernest Renan - ein plébiscit de tous les jours, aus dem sich jedoch keine Anknüpfungspunkte für die tatsächliche Handhabung der Staatsgewalt ergeben. In der Zwischenkriegszeit hatten utopische Visionen von einer plebiszitär-demokratischen Gesellschaftsordnung Konjunktur, während die Republik zunächst in die Anarchie und dann in den Totalitarismus abglitt. Die Entwicklung der Jahre 1932/33 führt jedem vor Augen, dass das Plebiszit stets fiktiv, losgelöst von einer konkret-empirisch wahrnehmbaren Bezugsgröße, wohingegen politische Herrschaft real ist. 
Staatsvolk, wie in Art. 20 II 1 GG angesprochen, ${ }^{81}$ und aktivbürgerschaftlicher Bezugspunkt der Staatsgewalt, Art. 20 II 2 GG) ${ }^{82,83}$ der Eindimensionalität personalistischer Zurechnungsmuster („Repräsentations- und Legitimationsketten") entgegen, weisen damit jede Eindeutigkeit demokratischer Repräsentation zurück. Die Ergänzung parlamentarischer durch plebiszitäre und partizipatorische Beteiligungsformen ${ }^{84}$ geht mit einer Zerfaserung hoheitlicher Aufgabenwahrnehmung zwischen kommunaler, nationaler und supranationaler Ebene einher. ${ }^{85}$ In der Postdemokratie kann „Repräsentation“ als

- Elitenherrschaft, ${ }^{86}$

- effektive Einwirkung auf die Staatsgewalt („,die Fähigkeit, etwas tun zu können“) ${ }^{87}$

- Spaltung des politischen Systems in Regierung und Opposition, ${ }^{88}$

81 BVerfGE 83, 37 (51); 83, 60 (71 f.).

82 BVerfGE 13, 54 (95); 83, 37 (50 f.).

83 Siehe zu den Spannungen zwischen emprischem und normativem Demosbegriff auch: C. Möllers, Drei Dogmen der etatistischen Demokratietheorie in: H.M. Heinig/J.P. Terhechte (Hrsg.), Postnationale Demokratie, Postdemokratie, Neoetatismus, 2013, S. 131 (132).

84 Dazu im Allgemeinen: H. Rossen-Stadtfeld, Beteiligung, Partizipation und Öffentlichkeit in: W. Hoffmann-Riem/E. Schmidt-Aßmann/A. Voßkuhle (Hrsg.), GVwR II, 2. Auflage 2013, § 29, Rn. 1 ff. A. Rinken, Demokratie und Hierarchie. Zum Demokratieverständnis des Zweiten Senats des Bundesverfassungsgerichts in: Redaktion Kritische Justiz (Hrsg.), Demokratie und Grundgesetz, 2000, S. 125 (135) kennzeichnet Betroffenenpartizipation aus Sicht der vom BVerfG beispielhaft in E 93, 37 vertretenen ,monistischen“ Demokratiekonzeption in kritischer Absicht als „demokratisches Ärgernis“. Ablehnung durch BVerfGE 83, 37 (51). Vermittelnd: E. Schmidt-Aßmann, Verwaltungslegitimation als Rechtsbegriff, AöR 116 (1991), S. 329 (349): Der Gedanke der Betroffenenpartizipation gehöre den ideellen Schichten des Demokratieprinzips an.

85 F.C. Mayer, Kommentar: Vom Demokratiediskurs zum Identitätsdiskurs - gefühlte Demokratie und die Folgen in: H.M. Heinig/J.P. Terhechte (Hrsg.), Postnationale Demokratie, Postdemokratie, Neoetatismus, 2013, S. 19 (22).

86 J. Schumpeter, Kapitalismus, Sozialismus und Demokratie, 8. Auflage 2005, S. $427 \mathrm{ff}$. In Schumpeters Tradition: A. Körösényi, Political Representation in Leader Democracy, Democracy and Opposition 40 (2005), S. 358 ff.

87 K. Ross, Demokratie zu verkaufen in: G. Agamben u.a., Demokratie? Eine Debatte, 2012, S. 96 (104).

88 N. Luhmann, Soziologische Aufklärung IV, 1987, S. 126 ff. 
- Deliberation der Aktivbürgerschaft, ${ }^{89}$

- politischer Versuch und Irrtum, ${ }^{90}$

- permanenter Skandal ${ }^{91}$

ausbuchstabiert werden.

Die repräsentativen Institutionen überbrücken eine der Demokratie eigentümliche Spannung zwischen der ins Kollektiv ausstrahlenden Willensmacht Einzelner und der den Einzelnen beschränkenden Souveränität des Kollektivs. Die repräsentative Demokratie macht aus der Menge ein Volk, ${ }^{92}$ verwandelt Mitgliedschaft in Zugehörigkeit. ${ }^{93}$ Nur im Wahlakt sind die Staatsbürger einander wirklich gleich. ${ }^{94}$ Nimmt man die Postdemokratie-These ernst, vermag aber gerade diese Staatsbürgergleichheit „demokratischen“ Ansprüchen an eine deliberativ-pluralistische Gesellschaft nicht zu genügen. In ähnlichem Sinne hat das Bundesverfassungsgericht in den Maastricht- und Lissabon-Urteilen verlangt, dass dem Aktivbürger eine substanzielle Wahl: eine Auswahl zwischen Personen und Konzepten bleiben muss. ${ }^{95}$ Aber das Postdemokratie-Argument führt noch weiter. Versteht man das Forum demokratischer Öffentlichkeit als tabula rasa, als eine von gesellschaftlicher Vermachtung frei gehaltene Spiegel-

89 J. Habermas, Faktizität und Geltung. Beiträge zur Diskurstheorie des Rechts und des demokratischen Rechtsstaats, 1992, S. 349 ff. Dazu: R. Forst, The Rule of Reasons. Three Models of Deliberative Democracy, Ratio Juris 14 (2001), S. 345 ff.; C. Stamatis, The Idea of Deliberative Democracy. A Critical Appraisal, Ratio Juris 14 (2001), S. 390 ff.; M. Nettesheim, Demokratisierung der EU und Europäisierung der Demokratietheorie - Wechselwirkungen bei der Herausbildung eines europäischen Demokratieprinzips in: H. Bauer/P.M. Huber/K.-P. Sommermann (Hrsg.), Demokratie in Europa, 2005, S. 143 (151 f.). Kritik bei: C. Möllers, Demokratie - Zumutungen und Versprechen, 3. Auflage 2012, S. 43: „Gute Gründe schaffen keine demokratische Legitimation“".

90 M. Kotzur, Demokratie als Wettbewerbsordnung, VVDStRL 69 (2010), S. 173 (185) im Anschluss an Karl Popper und Ralf Dahrendorf.

91 D. Bensaid, Der permanente Skandal in: G. Agamben u.a., Demokratie? Eine Debatte, 2012, S. $23 \mathrm{ff}$.

92 In der oben eingeführten Terminologie von P. Rosanvallon ließe sich statt von „Menge“ und „Volk“ von einer Spannung zwischen „Ideal-Volk“ und „SozialVolk“ sprechen (so ders., Demokratische Legitimität, BPB-Sonderausgabe 2013, S. 182).

93 R. Grawert, Staatsvolk und Staatsangehörigkeit in: J. Isensee/P. Kirchhof (Hrsg.), HStR II, 3. Auflage 2004, § 16, Rn. 5 mit Verweisen auf Georg Jellinek.

94 So die Interpretation der „monistischen“ Demokratietheorie bei: A. Hanebeck, Bundesverfassungsgericht und Demokratieprinzip, DÖV 2004, S. 901 (902).

95 BVerfGE 89, 155 (171 f.); 123, 267 (330). 
fläche der ,wirklichen“ Wünsche des Volkes, ist Sinnbild der Demokratie nicht der Parlamentsabgeordnete, dessen Gewissensvernunft das Gemeinwesen leitet, sondern der „Wutbürger“, der mit Erhebung seiner Stimme einen Lehrsatz des Marquis de Sade beherzigt: Der Aufstand müsse der Dauerzustand der Republik sein. ${ }^{96}$ Somit weist die Postdemokratie-These jede (in der Tradition der Federalist Papers stehende) ${ }^{97}$ (V-)Erklärung der repräsentativen zur ,eigentliche(n) Form der Demokratie“98 zurück. Sie moniert, dass die mit der Repräsentationstheorie verbundene Fiktion eines ideell einheitlichen Volkes die Demokratie mit dem Schatten einer „Metaphysik der Präsenz“ sowie einer „Metaphysik des Gesetzes als idealer Ausdrucksform des repräsentativ ermittelten Allgemeinwillens" belege. ${ }^{99}$

\section{Souveränität und Legitimität unter den Bedingungen der Postdemokratie}

Mit der Prekarität der repräsentativen Demokratie erodiert ihr Fundament: die Volkssouveränität. Wandern substanzielle Entscheidungen aus dem Einwirkungsbereich des Volkes in privat-publizistische Arrangements oder auf Ebenen jenseits des Staates ab, schwächt dies die Legitimation der repräsentativ-demokratischen Institutionen. Postdemokratische Analysen können deshalb nicht bei einer Repräsentationsskepsis ihr Bewenden haben, sondern müssen sich mit einem modernen Verständnis von Volkssouveränität und Legitimation befassen.

96 Dazu P. Rosanvallon, Demokratische Legitimität, BPB-Sonderausgabe 2013, S. 155.

97 J. Madison (Publius) in: A. Hamilton/ders./J. Jay (hg. von B. Zehnpfennig), Die Federalist Papers, 2007, Nr. 10, S. 93 ff. (besonders S. 99).

98 So der programmatische Titel des Beitrags von E.-W. Böckenförde, Mittelbare/ repräsentative Demokratie als eigentliche Form der Demokratie in: Festschrift für Kurt Eichenberger, 1982, S. $301 \mathrm{ff}$.

99 G. Frankenberg, Vorsicht Demokratie! Kritik der juridischen Versicherung einer Gesellschaft gegen die Risiken der Selbstregierung in: Redaktion Kritische Justiz (Hrsg.), Demokratie und Grundgesetz, 2000, S. 177 (181). 


\section{Souveränität}

Das Souveränitätsprinzip findet seinen verfassungsrechtlich verbindlichen Ausdruck in Art. 20 II 1 GG: „Alle Staatsgewalt geht vom Volke aus“. Ergänzend werden die Präambel und Art. 146 GG hinzu gezogen. ${ }^{100}$ Vom Volk kann als empirische Größe oder geistige Abstraktion, ${ }^{101}$ als Gesamtheit der Staatsangehörigen ${ }^{102}$ oder Betroffenheitsgemeinschaft ${ }^{103}$ die Rede sein. Das Souveränitätsprinzip verbindet die Demokratie mit ihrer Verwirklichungsform, dem Staat. ${ }^{104}$ Demokratie ist die „Konsequenz und Verwirklichung des Prinzips der Volkssouveränität"; 105 Souveränität ist der normative Kern der demokratischen Staats- und Regierungsform. ${ }^{106}$ Das moderne Souveränitätsverständnis stellt auf die Unabhängigkeit, nicht auf die Schrankenlosigkeit der Staatsgewalt ab. ${ }^{107}$ Kritiker wenden ein, dass in der Formulierung des Art. 20 II 1 GG nicht deutlich genug zum Ausdruck komme, dass die Ausübung der Souveränität über den Wahlakt hinaus „permanenten Charakter“ habe. ${ }^{108}$ Die Zentrierung der Staatsgewalt auf

100 R. Grawert, Staatsvolk und Staatsangehörigkeit in: J. Isensee/P. Kirchhof (Hrsg.), HStR II, 3. Auflage 2004, § 16, Rn. 27.

101 L. Heuschling, Krise der Demokratie und der juristischen Demokratielehre in Frankreich in: H. Bauer/P.M. Huber/K.-P. Sommermann (Hrsg.), Demokratie in Europa, 2005, S. 33 (47).

102 BVerfGE 83, 37 (51); 83, 60 (71). Siehe auch: E.-W. Böckenförde, Demokratie als Verfassungsprinzip in: J. Isensee/P. Kirchhof (Hrsg.), HStR II, 3. Auflage 2004, § 24, Rn. 26; R. Grawert, Staatsvolk und Staatsangehörigkeit in: Isensee/ Kirchhof (Hrsg.) aaO, § 16, Rn. 20 ff.; M. Brenner, Das Prinzip Parlamentarismus in: J. Isensee/P. Kirchhof, HStR III, 3. Auflage 2005, § 44, Rn. 25.

103 B.-O. Bryde, Die bundesrepublikanische Volksdemokratie als Irrweg der Demokratiethese, StWStP 5 (1994), S. 305 ff.; ders., Das Demokratieprinzip des Grundgesetzes als Optimierungsaufgabe in: Redaktion Kritische Justiz (Hrsg.), Demokratie und Grundgesetz, 2000, S. 59 ff.; U. Volkmann, Setzt Demokratie den Staat voraus?, AöR 127 (2002), S. 575 (586). Kritisch: S. Unger, Das Verfassungsprinzip der Demokratie, 2008, S. 43, $59 \mathrm{ff}$.

104 U. Volkmann, Setzt Demokratie den Staat voraus?, AöR 127 (2002), S. 575 (583 f.).

105 E.-W. Böckenförde, Demokratie als Verfassungsprinzip in: J. Isensee/P. Kirchhof (Hrsg.), HStR II, 3. Auflage 2004, § 24, Rn. 7.

106 P. Badura, Die parlamentarische Demokratie in: J. Isensee/P. Kirchhof (Hrsg.), HStR II, 3. Auflage 2004, § 25, Rn. 27.

107 A. Randelzhofer, Staatsgewalt und Souveränität in: J. Isensee/P. Kirchhof (Hrsg.), HStR II, 3. Auflage 2004, § 17, Rn. 23.

108 So S. Biernat, Demokratieprinzip im polnischen Verfassungssystem in: H. Bauer/ P.M. Huber/K.-P. Sommermann (Hrsg.), Demokratie in Europa, 2005, S. 79 
das Volk hatte zunächst den Sinn, das Trägersubjekt politischer Herrschaft gegen konkurrierende Mächte, insbesondere gegen das Gottesgnadentum zu bestimmen. In zeitgenössischem Kontext wendet sich das Souveränitätsprinzip gegen die Informalität politischer Entscheidungen im Gewande der Expertise. ${ }^{109}$ Mit der Postdemokratie-These lässt sich behaupten: Würde man heute erneut eine Unabhängigkeitserklärung verfassen, müsste sie als Absageerklärung an die Alternativlosigkeit technizistischer Politikprozesse formuliert werden. Entsprechend der Doppelwertigkeit des Demosbegriffs (s.o.) wird der dem Staatsangehörigkeitsband aufgeprägte Zugehörigkeitsgedanke ${ }^{110}$ als ,freie Selbstbestimmung aller"111 gedeutet. Hiernach ist ,souverän“ die Effektivität der Tat, ${ }^{112}$ nicht die Inklusion/Exklusion von Entscheidungsträgern. Der Volksbegriff wird mit dem Verfassungsbegriff verwoben, wenn - in Anlehnung an Bruce Ackerman - die Prävalenz der Verfassung vor dem einfachen Gesetz mit dem Vorrang des verfassungsmäßigen Willens eines ,ewigen“"Volkes vor den temporären Launen einer sich von Tag zu Tag Gesetze gebenden ,sterblichen“ Generation begründet wird. ${ }^{113}$ Dieser Kompass führt jedoch mit Friedrich August von

(81 f.) mit Blick auf die polnische Verfassungsdiskussion, die am aktuellen Wortlaut des Art. 4 I der polnischen Verfassung vom 2. April 1997 („Die oberste Gewalt in der Republik Polen steht dem Volk zu“ - so die Übersetzung auf http.// www.verfassungen.eu/pl/index.htm; zuletzt besucht am: 17. April 2015; Biernats Alternativübersetzung aaO, S. 80 lautet: „Die hoheitliche Gewalt in der Republik Polen gehört dem Volk“) mit rechtsvergleichendem Blick auf Art. 20 II 1 GG das Souveränitätselement betone.

109 Dazu: C. Möllers, Demokratie - Zumutungen und Versprechen, 3. Auflage 2012, S. 104.

110 P. Kirchhof, Der demokratische Rechtsstaat - die Staatsform der Zugehörigen in: J. Isensee/ders. (Hrsg.), HStR IX, 1. Auflage 1997, § 221.

111 B.-O. Bryde, Das Demokratieprinzip des Grundgesetzes als Optimierungsaufgabe in: Redaktion Kritische Justiz (Hrsg.), Demokratie und Grundgesetz, 2000, S. 59 (60) mit Verweis auf BVerfGE 5, 85 (147); 44, 125 (142).

112 Zum Souveränitätsprinzip als Effektivitätsgebot: BVerfGE 47, 253 (275); 77, 1 (40); 83, 60 (72 f.); 93, 37 (66 f.). Dazu: E.-W. Böckenförde, Demokratie als Verfassungsprinzip in: J. Isensee/P. Kirchhof (Hrsg.), HStR II, 3. Auflage 2004, § 24 , Rn. 11. Kritisch (im Effektivitätsgebot vermischten sich normative mit deskriptiv-empirischen Kriterien): T. Blanke, Funktionale Selbstverwaltung und Demokratieprinzip in: Redaktion Kritische Justiz (Hrsg.), Demokratie und Grundgesetz, 2000, S. 32 (41 f., 46).

113 B. Ackerman, La démocratie dualiste in: M. Troper/L. Jaume (Hrsg.), 1789 et l'invention de la Constitution, 1989, S. 191 ff. Dazu: L. Heuschling, Krise der Demokratie und der juristischen Demokratielehre in Frankreich in: H. Bauer/P.M. 
Hayeks „Demarchie“ in autoritäres Fahrwasser. Die Demarchie weist eine Reihe überzeitlich-gültiger konstitutioneller Prinzipien aus, in deren Rahmen eine Elite von Politikern die sachnotwendigen Entscheidungen trifft. ${ }^{114}$

\section{Legitimation}

Der Volksbegriff stellt die Weichen zur Definition des „legitimen“ Zustands einer politischen Einheit. Pierre Rosanvallon differenziert zwischen drei Formen demokratischer Legitimität, denen drei jeweils unterschiedliche Volksbegriffe entsprechen:

- das Wahl-Volk (peuple-électoral) erzeugt auf der Grundlage der Wahlrechtsgleichheit und -allgemeinheit eine in der Gewissensprägung des repräsentativen Mandats aufscheinende Legitimität der Unparteilichkeit;

- das Ideal-Volk (peuple-principe) trägt zu einer Legitimität der Reflexivität bei, als deren Treuhänder Kontrollinstanzen, insbesondere die Verfassungsgerichtsbarkeit, fungieren;

- das Sozial-Volk (peuple-social) gebiert durch seine reale Präsenz in Verwaltungsverfahren und Volksgesetzgebung eine Legitimität der Nähe. ${ }^{115}$

Offen bleibt dabei freilich, ob Demokratie in der Tradition neuzeitlicher politischer Ethik Richtigkeit, ${ }^{116}$ gar Wahrheit erreichen soll oder ob es ihr

Huber/K.-P. Sommermann (Hrsg.), Demokratie in Europa, 2005, S. 33 (59 f.). Zur französischen, im 19. Jahrhundert mit antidemokratischem Unterton geführten Debatte um das ,generationenübergreifende Volk“: P. Rosanvallon, Demokratische Legitimität, BPB-Sonderausgabe 2013, S. 183. Ähnlich P. Rosanvallon, Demokratische Legitimität, BPB-Sonderausgabe 2013, S. 176: Der Vorrang der Verfassung entstehe auf Grund ihrer „Funktion (...), für eine offene Zukunft zu sorgen, damit sich das Verhältnis zwischen Mehrheit und Minderheit nicht verfestigt".

114 F.A. von Hayek, Law, Legislation and Liberty Vol. 3 (The Political Order of a Free People), 1982, S. $38 \mathrm{ff}$.

115 P. Rosanvallon, Demokratische Legitimität, BPB-Sonderausgabe 2013, S. 15, $161 \mathrm{f}$. und passim.

116 So auch noch für das moderne Staatsrecht mit einem Schwerpunkt auf demokratieprinzipiell radizierten Verfahrensgarantien: A. Bleckmann, Staatsrecht I Staatsorganisationsrecht, 1993, §9, Rn. 273, 277, 282 gegen eine von ihm als 
vornehmlich um die „Symmetrie zwischen bürgerschaftlichen Lasten und Berechtigungen" ${ }^{117}$ gehen soll. ${ }^{118}$ Unentschieden bleibt auch, ob Legitimation als ein relativistisches Konzept zu begreifen ist - legitim ist dann jede Art von Entscheidungsinhalt, sofern ein formaler Zurechnungszusammenhang zum Souverän hergestellt ist - oder ob sie hoheitliches Handeln auf die Wahrung der Menschenrechte, Essentiale der Republik, festlegt. Auf diese Grundspannung ist ein Gutteil der (bis in die französische Revolutionszeit zu Condorcet und seinen Vorstellungen von einer ,komplexen Souveränität“" zurück führenden) ${ }^{119}$ Auseinandersetzungen um die Rolle funktionaler Legitimationskriterien bzw. eines ,pluralistischen“, an Output-Aspekten orientierten Legitimationsverständnisses zurückzuführen. ${ }^{120,121}$ Legitimationstheorien gehen klassischerweise davon aus, dass das Volk ein Mandat auf Zeit erteilt, zur Herrschaft nach dem Mehrheitsprinzip (Art. 42 II 1, 52 III 1, 54 VI 1, 61 I 3, 63 II 1, 67 I 1, 68 I 1, 79 II, 115a I 2, 115e I, 115h II i.V.m. Art. 121 GG) in einem durch den Nationalstaat konfigurierten Solidaritätsraum ermächtigt. Herrschend ist noch im-

rousseauistisch eingestufte moderne Tradition der Demokratie als kollektiver Selbstbestimmung.

117 E. Schmidt-Aßmann, Verwaltungslegitimation als Rechtsbegriff, AöR 116 (1991), S. 329 (355).

118 Siehe dazu auch: H.-H. Trute, Die demokratische Legitimation der Verwaltung in: W. Hoffmann-Riem/E. Schmidt-Aßmann/A. Voßkuhle (Hrsg.), GVwR I, 2. Auflage 2012, § 6, Rn. 5.

119 Dazu: P. Rosanvallon, Demokratische Legitimität, BPB-Sonderausgabe 2013, S. 159.

120 Zum pluralistischen Legitimationsmodell und seinen begrifflichen Voraussetzungen: H.-H. Trute, Die demokratische Legitimation der Verwaltung in: W. Hoffmann-Riem/E. Schmidt-Aßmann/A. Voßkuhle (Hrsg.), GVwR I, 2. Auflage 2012, § 6, Rn. 21 ff.; M. Jestaedt, Radien der Demokratie: Volksherrschaft, Betroffenenpartizipation oder plurale Legitimation? In: H.M. Heinig/J.P. Terhechte (Hrsg.), Postnationale Demokratie, Postdemokratie, Neoetatismus, 2013, S. 3 (9, $12 \mathrm{ff}$.).

121 Kritik an der Output-Legitimation bei: C. Möllers, Demokratie - Zumutungen und Versprechen, 3. Auflage 2012, S. 22: Da die Demokratie kein gutes Leben verspreche, könne dessen Gelingen oder Misslingen auch keine Auswirkungen auf die demokratische Legitimation haben. 
mer ein volksmonistisches ${ }^{122}$ (nicht parlamentsmonistisches) $)^{123}-$ um das Volk als Legitimationssubjekt, nicht um das Parlament als prävalentes Entscheidungsgremium zentriertes - Legitimationsverständnis, das mit pluralistischen, für eine Vielzahl verschiedener Legitimationsquellen offenen Legitimationstheorien konfrontiert wird. ${ }^{124}$ Mit dem demokratischen Monismus verbindet sich der Gedanke einer „repräsentative(n) Wählerdemokratie“, in deren Wahlakten der Gemeinwille „unmittelbar und uneingeschränkt" zum Ausdruck komme. ${ }^{125,126}$ Postdemokratische Analysen betrachten demgegenüber die unter der Oberfläche des Demos zu verzeichnende Aufsplitterung in politische Parteien und Verbände, abzulesen an der föderal vermittelten Segmentierung des Bundevolks in politische Untereinheiten auf Wahlkreisebene. ${ }^{127}$ Sie betonen, dass demokratische Legitimation wesentlich von Verfahren abhängt. Dadurch verbietet sich jedes Ausspielen von Legitimität gegen Legalität. Zugleich validiert das

122 Diese „volksmonistische“, auf die Einheit des Staatsvolks abstellende Konzeption läuft im föderal gegliederten Staat auf die merkwürdige Pointe hinaus, dass das Bundesvolk die Landesvölker konsumiert. Somit sind die Bundesländer (und ebenfalls die kommunalen Gebietskörperschaften) Beispiele „für demokratische Strukturen außerhalb der eigentlichen Staatssphäre" (S. Augsberg, Wer ist das Volk?, ZG 2012, S. 251 (258)). Anders jedoch BVerfGE 83, 60 (74).

123 P. Badura, Die parlamentarische Demokratie in: J. Isensee/P. Kirchhof (Hrsg.), HStR II, 3. Auflage 2004, §25, Rn. 6. Eine parlamentsmonistische Legitimationstheorie würde die historische Differenzierung zwischen Trägerschaft der Staatsgewalt und Form der Selbstregierung verkennen (Badura aaO, Rn. 7).

124 Zum Streitstand: S. Unger, Das Verfassungsprinzip der Demokratie, 2008, S. 55 ff.; H. Kube, Zu Rechtsstaatlichkeit, Demokratie und der Autonomie rechtlicher Rationalität - im Spiegel der Haushaltsrechtsreform, DV 35 (2002), S. 507 (517f.).

125 P. Rosanvallon, Demokratische Legitimität, BPB-Sonderausgabe 2013, S. 152. Diese Definition von „Demokratie“ beruhe, so Rosanvallon aaO, auf drei Prämissen: „der Gleichsetzung des Wählerwillens mit dem Gemeinwillen, der Identifizierung der Wähler mit dem Volk und der Einordnung der politisch-parlamentarischen Tätigkeit in die Kontinuität der Wahlen“.

126 Zum geistesgeschichtlichen Hintergrund der mit „Monismus“/„Etatismus“ und „Pluralismus“ bezeichneten Legitimationskonzepte: T. Groß, Grundlinien einer pluralistischen Interpretation des Demokratieprinzips in: Redaktion Kritische Justiz (Hrsg.), Demokratie und Grundgesetz, 2000, S. 93 (95): Der „Monismus“ führe auf Hobbes, der „Pluralismus“ auf Locke zurück.

127 D. Schefold, Gewaltenteilung und alternative Modelle demokratischer Legitimation in: Redaktion Kritische Justiz (Hrsg.), Demokratie und Grundgesetz, 2000, S. 148 (154). 
Verfahren eine Reihe unterschiedlicher Legitimationswege. ${ }^{128}$ An die organisatorisch-personelle Legitimationskette ${ }^{129}$ lagern sich Stränge sachlich-inhaltlicher und funktional-institutioneller Legitimation an. ${ }^{130},{ }^{131} \mathrm{Un}-$ geklärt bleibt freilich,

- ob einer der genannten Legitimationsmodi als vorrangig zu betrachten ist, ${ }^{132}$

- inwiefern Defizite einer Legitimationsform durch korrelierende Legitimationsbeiträge kompensiert werden können,

- schließlich, ob neben der demokratischen Legitimation im engeren Sinne autonome Legitimationsformen zur Demokratie beitragen können.

128 H.-H. Trute, Die demokratische Legitimation der Verwaltung in: W. HoffmannRiem/E. Schmidt-Aßmann/A. Voßkuhle (Hrsg.), GVwR I, 2. Auflage 2012, §6, Rn. $7 \mathrm{ff}$.

129 E.-W. Böckenförde, Demokratische Willensbildung und Repräsentation in: J. Isensee/P. Kirchhof (Hrsg.), HStR III, 3. Auflage 2005, § 34, Rn. 17 ff. Dazu: N. Petersen, Demokratie und Grundgesetz. Veränderungen des Demokratieprinzips in Art. 20 Abs. 2 GG angesichts der Herausforderungen moderner Staatlichkeit, JöR n.F. 58 (2010), S. 137 (150 ff.; dort auf S. 159, Fn. 136 weitere Nachweise zur (Um-)Deutung der Legitimationskettentheorie als Konzeption politischer Responsivität).

130 BVerfGE 49, 89 (125); 68, 1 (88).

131 BVerfGE 83, 60 (72). Siehe auch: E.-W. Böckenförde, Demokratie als Verfassungsprinzip in: J. Isensee/P. Kirchhof (Hrsg.), HStR II, 3. Auflage 2004, § 24, Rn. $14 \mathrm{ff}$.

132 Während ältere, strikt monistische Demokratiemodelle die Prävalenz der personal wirksamen Weisungs- und Unterrichtungskette gegenüber gesetzlicher Programmierung oder funktional legitimierter Selbstprogrammierung der Staatsgewalt in den Vordergrund stellen (wie das Gericht in formalem Rechtsstaatsverständnis als bouche de la loi auftritt, so das Parlament im demokratietheoretischen Formalismus als Steuermann, der seine Mannschaft - die Exekutive - befehligt), so kommt es nach neuerer Rechtsprechung auf ein insgesamt zureichendes Legitimationsniveau, auf eine in der Summe effektive Herrschaftsvermittlung an (BVerfGE 83, 60 (72); 93, 37 (66); 107, 59 (87); BVerwGE 106, 64 (74)). Dazu: E. Schmidt-Aßmann, Verwaltungslegitimation als Rechtsbegriff, AöR 116 (1991), S. 329 (366 ff.); H.-H. Trute, Die demokratische Legitimation der Verwaltung in: W. Hoffmann-Riem/E. Schmidt-Aßmann/A. Voßkuhle (Hrsg.), GVwR I, 2. Auflage 2012, §6, Rn. 56 f. Die Argumentation mittels des Legitimationsniveaus wird vor dem Hintergrund einer vom BVerfG in E 93, 37 vertretenen monistischen Demokratiekonzeption als unhaltbar kritisiert von T. Blanke, Funktionale Selbstverwaltung und Demokratieprinzip in: Redaktion Kritische Justiz 
Die hierzu parallel geführte Debatte in der Politikwissenschaft legt den Abschied von der personalen Einsetzungslegitimation, die Abstandnahme von der liberalistischen Imagination des Volkes als großes Individuum und von demokratischer Freiheit als der Individualfreiheit komplementäre Gestaltungsmacht nahe; dies jedoch nicht, weil normativ nicht vertretbar, sondern auf Grund einer vermeintlichen Überholung liberalistisch-personalistischer Legitimationsmaßstäbe durch die Wirklichkeit. Statt der ,unbestimmte(n) Allgemeinheit" 133 des Demos streichen sie die Gestaltungsmacht des einzelnen Demokraten heraus. Somit erlangen Grundrechte auf freie Meinungsäußerung, Versammlungs- und Vereinigungsfreiheit eine besondere „bürgerrechtliche“ Funktionalität für die demokratische Willensbildung. ${ }^{134}$ Sie spiegeln den bislang in die tieferen Schichten des Demokratieprinzips gebannten individualistischen Aspekt öffentlicher Einflussnahme wider. In einer freiheitlichen, rechtsstaatlich umrahmten Demokratie bedarf die öffentliche Willensbildung der diskursiven Offenheit, ${ }^{135}$ sichergestellt durch Grundrechte auf politische Kommunikation (voice). ${ }^{136}$ Mit Christoph Möllers: „Demokratien sind nicht repräsentativ, sondern expressiv"; sie bilden keinen demokratischen Willen ab, sondern erzeugen diesen durch ein auf freier Gleichheit beruhendes Verfahren der Willensbildung. ${ }^{137}$ In jüngerer Zeit wird die Input-Output-Orientierung des demokratietheoretischen Legitimationsdiskurses in der Politikwissenschaft in eine rechtstheoretisch-rechtsdogmatische Auseinandersetzung um den Prinzipien- oder Regelcharakter des Art. 20 II 1 GG ${ }^{138}$ übersetzt.

(Hrsg.), Demokratie und Grundgesetz, 2000, S. 32 (46): „Lediglich bei (Machtfragen, Anm. J.S.) lässt sich (...) eine graduelle Abstufung nach Effektivitätsund Niveaukriterien vornehmen. Demgegenüber bewähren sich Legitimationen, normative Rechtfertigungen wie moralische Urteile generell nach einem `Alles oder Nichts-Schema': Entweder sie tragen oder sie versagen, entweder sind sie wahr oder falsch".

133 BVerfGE 83, 37 (55).

134 BVerfGE 7, 198 (208); 12, 113 (125); 20, 56 (97); 35, 202 (221 f.); 59, 231 (266). Siehe auch: E.-W. Böckenförde, Demokratie als Verfassungsprinzip in: J. Isensee/P. Kirchhof (Hrsg.), HStR II, 3. Auflage 2004, § 24, Rn. 36 ff.

135 E.-W. Böckenförde, Demokratie als Verfassungsprinzip in: J. Isensee/P. Kirchhof (Hrsg.), HStR II, 3. Auflage 2004, § 24, Rn. 40.

136 Klassisch: BVerfGE 7, 198 (205 ff.). Zum Einfluss der öffentlichen Meinung auf die Staatsorgane: BVerfGE 20, 56 (99). Dazu: S. Unger, Das Verfassungsprinzip der Demokratie, 2008, S. 27, 31.

137 C. Möllers, Demokratie - Zumutungen und Versprechen, 3. Auflage 2012, S. 28.

138 S. Unger, Das Verfassungsprinzip der Demokratie, 2008, S. 104 ff. 
Postdemokratie bildet sich mit Blick auf verselbständigte Verwaltungseinheiten und ministerialfreie Räume ${ }^{139}$ in einem Legitimationspluralismus ab. Daraus erhellt, dass sich demokratische Legitimität nicht auf einen „Ableitungspurismus“ ${ }^{\text {"140 }}$ reduzieren lässt, sondern je nach zu legitimierender Gewaltausübung stärker die soziale Anerkennung von Herrschaft ${ }^{141}$ oder das Ergebnis des Legitimationsvorgangs in den Mittelpunkt rückt. ${ }^{142,143}$ Eine weitere Facette dieser Auseinandersetzung ist die von Léon Duguit und Maurice Hauriou im Frankreich der zwanziger Jahre angeführte Diskussion um die funktionale Legitimation der Staatsgewalt, die man in der Befriedigung der gesellschaftlichen Bedürfnisse sah (und in deren Konsequenz der service public zum zentralen Legitimationstopos wurde). ${ }^{144}$

\section{Schluss}

Es besteht kein Anlass, der repräsentativen Demokratie das Totenglöckchen zu läuten. Die postdemokratisch-repräsentationskritische Analyse legt zwar manche Schwachstellen des Parlamentarismus offen, formuliert jedoch keine grundstürzenden Einsichten gegen die hergebrachte verfassungsrechtlich fundierte politische Praxis. Da die Postdemokratie-These auf die Legitimationsprobleme des beginnenden 21. Jahrhunderts antwortet, könnte schon bald eine Diskussion über das Ende der Postdemokratie oder über eine Renaissance der Repräsentation geführt werden. Letzteres wäre zu wünschen.

139 T. Blanke, Funktionale Selbstverwaltung und Demokratieprinzip in: Redaktion Kritische Justiz (Hrsg.), Demokratie und Grundgesetz, 2000, S. 32 (50 f.).

140 T. Blanke, Funktionale Selbstverwaltung und Demokratieprinzip in: Redaktion Kritische Justiz (Hrsg.), Demokratie und Grundgesetz, 2000, S. 32 (52).

141 H.-H. Trute, Die demokratische Legitimation der Verwaltung in: W. HoffmannRiem/E. Schmidt-Aßmann/A. Voßkuhle (Hrsg.), GVwR I, 2. Auflage 2012, §6, Rn. 2; S. Müller-Franken, Die demokratische Legitimation öffentlicher Gewalt in Zeiten der Globalisierung, AöR 134 (2009), S. 542 (547).

142 A. Voßkuhle/G. Sydow, Die demokratische Legitimation des Richters, JZ 2002, S. 673 (674).

$143 \mathrm{Zu}$ verschiedenen Legitimitätsbegriffen: N. Petersen, Demokratie und Grundgesetz. Veränderungen des Demokratieprinzips in Art. 20 Abs. 2 GG angesichts der Herausforderungen moderner Staatlichkeit, JöR n.F. 58 (2010), S. 137 (142 ff.).

144 Klassisch: L. Duguit, Les Transformations du droit public, 1913, S. 52. Dazu: P. Rosanvallon, Demokratische Legitimation, BPB-Sonderausgabe 2013, S. 52 f. 